\title{
Using paradox theory to understand responses to tensions between service and training in general surgery.
}

CLELAND, J., ROBERTS, R., KITTO, S., STRAND, P. and JOHNSTON, P.

This is the peer reviewed version of the following article: CLELAND, J., ROBERTS, R., KITTO, S., STRAND, P. and JOHNSTON, P. 2018. Using paradox theory to understand responses to tensions between service and training in general surgery. Medical Education, 52(3), pages 288-301, which has been published in final form at https://doi.org/10.1111/medu.13475. This article may be used for non-commercial purposes in accordance with Wiley Terms and Conditions for Use of Self-Archived Versions. 
Using paradox theory to understand responses to tensions between service and training in general surgery

Jennifer Cleland ${ }^{1}$, Ruby Roberts ${ }^{1}$, Simon Kitto ${ }^{2}$, Pia Strand ${ }^{3}$, Peter Johnston ${ }^{4}$

${ }^{1}$ Centre for Healthcare Education Research and Innovation (CHERI), School of Medicine, Dentistry and Nutrition, University of Aberdeen, Aberdeen, UK

${ }^{2}$ Department of Innovation in Medical Education, University of Ottawa, Canada

${ }^{3}$ The Faculty of Medicine Centre for Teaching and Learning, Lund University, Sweden

${ }^{4}$ NHS Education for Scotland, Northern Deanery, Aberdeen, UK

\section{Corresponding author:}

Professor Jennifer Cleland

John Simpson Chair of Medical Education

School of Medicine and Dentistry

University of Aberdeen

Foresterhill

Aberdeen

AB25 2ZD

Tel: 01224437257

Email: jen.cleland@abdn.ac.uk 


\begin{abstract}
Introduction

The tension between service and training in pressured healthcare environments can have a detrimental impact on training quality and job satisfaction. Yet the management literature proposes that competing demands are inherent in organisational settings: it is not the demands as such that lead to negative outcomes but how people and organisations react to opposing tensions. We explored how key stakeholders responded to competing service-training demands in a surgical setting which had recently gone through a highly-publicised organisational crisis.
\end{abstract}

\title{
Methods
}

This was an explanatory case study of a general surgery unit. Public documents informed the research questions and this data was triangulated with semi-structured interviews $(n=14)$ with key stakeholders. Data coding and analysis were initially inductive but, after the themes emerged, we used a paradox lens to group themes into four contextual dimensions: performing, organising, belonging and learning.

\section{Results}

Tensions were apparent in the data, with managers, surgeons and trainees/residents in conflict with each other due to different goals/priorities and divergent perspectives on the same issue of balancing service and training (performing). This adversely impacted on relationships across and within groups (belonging, learning) and led to individuals prioritising their own goals rather than working for the "greater good" (performing, belonging). Yet while relationships and communication improved, the approach to getting a better balance maintained the "compartmentalisation" of training (organising) rather than acknowledging training and service cannot be separated.

\section{Discussion}

Stakeholder responses to the tensions provided temporary relief but were unlikely to lead to real change if the tension between service and training is considered an interdependent and persistent paradox. Reframing the service-training paradox in this way may encourage adjusting responses to create effective working partnerships. Our findings add to the body of knowledge on this topic, and will resonate with all those engaged in surgical and other postgraduate training. 


\section{$\underline{\text { Introduction }}$}

Healthcare faces multiple, competing demands simultaneously (1-4). At the same time as delivering safe and effective patient care, hospitals and other healthcare facilities are also charged with educating future generations of health professionals $(5,6)$. Moreover, healthcare does not exist in a vacuum. Hospitals and health systems in many countries, including our own (the UK), are struggling to cope with an ageing population, the proliferation of chronic disease management and soaring costs within a climate of growing financial parsimony (7), increasing bureaucracy, regulatory control (including duty hours regulations) and emphasis on performance management (e.g., targets) (8).

Service and training compete for limited time and resources in this pressured environment (9-12). Less time is available for faculty to teach, and residents also have less time to achieve their competences (13-16). These tensions are well described, particularly in the medical press, and other research highlights that they are threatening trainees' quality of training (17); adversely influencing trainee and senior doctor job satisfaction (18-20), and discouraging trainees from working in particular specialties and locations (13). This discourse regarding the tension between service and training is well known and global $(12,13,21)$, but what is under-researched are ways in which it could be appropriately addressed.

The management literature may provide insight into potential solutions. For example, it proposes that competing demands are inherent in organisational settings and it is not the demands as such that lead to negative outcomes such as job dissatisfaction or burnout. Rather the important factor is how people and organisations react to opposing tensions in situ, on a day-to-day basis (22). To the best of our knowledge, it appears that how stakeholders within the organisational setting of a hospital manage and respond to the tensions between service and training has not been directly explored. Yet with the pressures on healthcare environments ever-increasing, educational or organizational change depends on knowing more about how these tensions play out in the clinical workplace.

Paradox theory provides a useful lens to do so. Paradox theory refers to a group of theories with similar lines of thinking developed to help create new knowledge by considering opposing viewpoints and incompatible positions and raising awareness for their co-existence in the social context of an organisation. Paradox is a term with a long history and multiple meanings $(23,24)$ but in the organisational context, paradox is a social construct, referring to "the simultaneous existence of two inconsistent states, such as between innovation and efficiency, collaboration and competition, or new and old" $(25$, p. 703$)$ 
Paradox theory assumes that the tensions between two states, or elements, such as service and training, "exist simultaneously and persist over time" (26, p.382); unresolvable because of different stakeholders, such as trainers and trainees, or clinicians and managers, having divergent goals and positions $(27,28)$; yet not always salient until something - such as an organisational crisis of some sort - disrupts the status quo, then they are rendered visible $(29,30)$.

There are four main types of paradox, each of which are theorised to occur in different ways (see Table 1). Tensions also exist across these categories $(26,28)$. Learning and performing tend to create tensions between the current purpose and change. Organising and performing reflect challenges between means and outcomes. Belonging and performing tensions reflect the tensions between individual identities and change goals, while belonging and organising tensions highlight the paradox of personal good versus the common good.

Table 1 about here.

Paradox theory provides a lens for organising and interpreting data (34-36) as well as a framework to examine the nature of responses to paradox. While resolution is not achievable - it is not a matter of training over service, or service over training (37) - how different stakeholders respond to competing demands will influence the ongoing nature of paradoxical tensions (26) and the impact of these tensions (in this case, their impact on both educational and service processes). Responses can be defensive or active, with the former providing short-term relief but no new ways with work within the paradox, and the latter representing attempts to deal with paradox on a longer-term basis. Jarzabkowski et al. (31) provide an overview of a large literature on responses to paradox, which is partially reproduced with permission as Table 2 .

Table 2 about here.

Organizations and individuals must consider solutions which require managing paradoxical tensions constructively, rather than trying to resolve or circumvent them $(23,26,30)$.

Our aim was to explore how those working in a general surgery department in a university teaching hospital experienced, perceived and responded to competing demands. We chose surgery as the context for this study as surgical training is proposed to have its own character, separate from yet 
sharing common characteristics with the broader field of medical education, yet it is a relatively under-researched and under-theorised field in medical education research (38). Much of the focus on learning in surgery to date has been concerned with examining whether a particular educational approach works or not (e.g., there is a vast literature on 'VR-to-OR' [virtual reality to operating room] research in surgical education: 39), but there is now increasing interest in considering questions about surgical training within the complexity of the workplace $(38,40-42)$.

Using a paradox lens to organise and interpret our data $(34,35)$, we sought to uncover more about the nature of service-training tension, how service and training inter-related and how stakeholders responded to them in a real-life, surgical setting.

In using this theoretical lens, we hope to give a new perspective on how the tensions between surgical service and training can be conceptualised, and extend knowledge about the management of surgical education specifically and postgraduate clinical education generally. Our specific research question was: how to those involved in surgical education and training manage and respond to tensions between service and training? 


\section{Methods}

We took an explanatory case study approach $(36,43,44)$, one which seeks to explain how or why a contemporary phenomenon occurs, to examine the tensions between service and training within the unit of analysis, or 'microsystem' (45), of a general surgery department in a large public, teaching hospital (see below). We drew on documentary evidence to inform the research focus and then used semi-structured interviews as our primary source of evidence. While we were interested in exploring participants' experiences of the tensions between service and training, and how other organisational processes may impact on training, our main focus was on identifying their reactions/attitudes to these tensions and processes.

\section{Context}

We selected an extreme case $(36,46,47)$ in order to maximise the richness of information on the tension between service and training, and the consequences of this tension.

The context was a clinical department of general surgery based within a large, public-sector (National Health Service) university teaching hospital in the UK. The department delivers surgical inpatient and outpatient services. It also supervises the education of medical students, doctors and other healthcare professional students and groups (see Box 1 for an overview of medical training in the UK). Most consultant-level doctors take on formal roles to support education and training. However, all healthcare staff are involved in medical training to some extent, with more senior trainees helping to support those earlier on in the training pipeline; the wider team working with the trainee and giving feedback on their performance; and managerial/administrative staff working to ensure rotas, theatres and clinics are appropriately staffed while adhering to working time regulations.

The general surgery unit was in the unusual (and unenviable) position of having critical reviews by the Royal College of Surgeons (England) and Healthcare Improvement Scotland. These were commissioned following very poor trainee feedback in a national feedback study run annually by the General Medical Council (GMC, UK) and a public dispute between Consultant (Attending) Surgeons and the hospital's management. The latter resulted in two senior surgeons being suspended from service. This led to a highly visible crisis $(49,50)$ which was played out in the local and national press.

While this may be considered an organisational disruption (51), the external reviews highlighted that tensions between service and training were not new in the general surgery unit; for example, they identified persistent poor communications and relationships between individuals and groups, with consequent adverse effects on the education and training of doctors. However, from the 
perspective of paradox theory, the external critical reviews, and subsequent enhanced monitoring status placed upon the unit by the GMC (see Box 1), were disruptions which foregrounded persistent tensions, and made these more salient to those working and training in the unit $(26,29,30)$. This situation provided us with the opportunity to observe tensions which may have otherwise have remained latent.

Box 1: A brief overview of postgraduate medical training in the UK ......

\section{Participants and data collection}

After obtaining ethical approval and appropriate institutional consents, criterion-based sampling of key stakeholders (52: learners, trainers, members of the extended surgical team, management) in combination with volunteer sampling (see next paragraph) was used to identify relevant individuals who had specific perspectival knowledge, experience and understanding of training in the unit at the time of the critical reviews. The sampling frame enabled the identification of a variety of individuals to generate a rich and comprehensive analysis of the local surgical training processes and environment. We aimed to recruit interviewees from different hierarchical levels (e.g., Consultants, doctors in training) and groups (e.g., doctors, managers) in order to achieve a rich, multi-perspective analytical description of the context.

The study was advertised via circular emails and short, informal presentations at surgical meetings. Recruitment was conducted via email. Positive responses were followed up by email providing more information about the study, and a convenient time and place for a face-to-face interview arranged. Those who agreed to take part in the study were invited to attend a semi-structured, one-to-one interview. We used the external review reports referred to earlier and the wider literature on surgical education and training $(13,53-55)$ to design some broad topics of enquiry, which were presented as open questions to help interviewees articulate their thoughts and experiences of working and/or training in the general surgery department prior to, and following, these reviews. The principal purpose of the interviews was to develop an understanding of the events, changes and related challenges from the perspective of our informants. The interview scheduled was piloted with a surgical trainee (resident), and refined on the basis of the content and process of that pilot interview. Our approach was iterative: we used our notes and recordings from early interviews to inform the development of additional questions for later interviews. 
The interviews were conducted by JC and/or RR. Both were "outsiders" to the study setting, with no involvement in clinical surgery or surgical education and training.

\section{Data analysis}

All interviews were audio recorded with participant permission, transcribed for analysis, and entered into NVIVO 10 qualitative data analysis software to help facilitate multi-analyst coding of the data. We treated all the interviews as one dataset and coding commenced after all the interviews had been completed. Initial data coding and analysis of the transcribed interviews was inductive, using thematic analysis to generate an initial, non-interpretative coding scheme (56) which was used to code all data. Analysis progressed via regular team meetings and telephone/skype discussions, where ongoing coding and comparisons were explored. Comparisons were made between codes and participants to explore differences and similarities in participants' perspectives. Analytical ideas were documented through memos and team correspondence that created an audit trail of the analytic process. On scrutinising the data, we were struck that many of the issues seemed to relate not only to direct tensions between service and training, but also to tensions between wider systems factors (e.g., staffing, handover processes, workload), individual factors (e.g., bullying, behavioural issues) and how these interacted (e.g., lack of support for educational supervisors [trainers]). It was this that led us to use Smith and Lewis's (26) paradox lens to help understand and explain the data, to illuminate the issues clearly, identify important factors and their potential relationships, and provide deeper understanding of the tensions, or paradoxes.

Rigour was ensured in a number of ways. Our research team was diverse (including a sociologist, educationalist, and a medical doctor as well as the two psychologists, one of whom has worked for many years in medical education). Our approach to working together was reflexive, to aid critical reflection on the interpretations of the data (57). Preliminary data analysis and the choice of theoretical framework were also discussed with (non-participant) clinical and research colleagues to explore if the findings seemed credible and reasonable (58). 


\section{$\underline{\text { Results }}$}

We were able to identify a mutually convenient time for interviews with 14 of the 18 people who we had approached to take part in the study (two of the remaining four people had moved away from the area). These 14 individual, semi-structured interviews were carried out during the time period January-April 2016. The mean length of the interviews was 40 minutes (from 25 to 80 minutes). Interviewees included those with formal roles in surgical education and training (consultant surgeons), nursing staff, students and trainees at all stages of surgical training, plus senior clinicians from other hospital specialities who had over-arching education and training roles, hospital administrators and managers. Eight participants were male, six female. To bring the research alive but at the same time assure anonymity, interviewees are referred to below only by number and broad role (e.g., $\mathrm{S}=$ Consultant surgeon; $\mathrm{T}=$ doctor in training (resident); $\mathrm{AM}=$ administrator or manager; $\mathrm{N}=$ nurse; $\mathrm{E}$ = educationalist (clinician with senior educational role but not a surgeon).

We have presented the data in the four category framework of organisational paradox $(23,26,30)$, and indicate the way in which each seemed to occur in terms of Jarzabkowski et al.'s (31) constructs of splitting, supressing, opposing and adjusting (see Table 2). While there are a number of different ways of presenting qualitative data, in this study we have interwoven results and theory together. Quotations are included to aid confirmability, to help the reader follow the logic of the story.

\section{Performing}

The notion of competing roles was apparent in the data, particularly in terms of reflecting on the difficulty delivering service and training: "how on earth are we supposed to do $x, y$ and $z$ when we're also supposed to deliver $a, b$ and $c$ ?" (P13E). More senior surgeons (those who were in training roles) struggled to manage the competing roles of being a clinician and a trainer, and caring for patients was typically prioritised over training: "sometimes I don't have time for a student" (P5S). Training was seen by learners as "squeezed into the gaps" (P2T) although individual differences (see Learning) were acknowledged - some surgeons were seen as more willing to "identify patients, do examinations and interact with the students" (P3T).

The Consultant surgeons were explicit about the competing demands of service and training, albeit that they tended to focus on the former (see above), but the focus of the trainees was achieving their competencies: "killing each other ... to get their procedures" (P4T). Trainees focused on their own needs (e.g. getting a specific number of procedures signed off) without considering the needs of other trainees or of the service (see also Belonging). For example, one trainee, nicknamed "king medic" by 
his peers, would leave his clinical work, without arranging cover, to go to theatre thus disrupting the rest of the team.

Trainees had clear views on the nature of activities, some of which were seen as training opportunities, others as service, or "just jobs" (P4T). Trainers had a different view of tasks, seeing many day-to-day tasks, or service activities, as inherently educational, but acknowledging at the same time that their perception was not shared by trainees: “maybe they sit in this meeting and don't realise it's a learning and training opportunity" (P12S).

Competing goals were also apparent between surgeons and managers. Consultant surgeons and trainees/residents at all levels of training perceived that management were "remote from the situation" (P6AM) and were "not listening to concerns about problems with staffing or training until it's almost too late" (P2T). The data suggested that the Consultant surgeons perceived that, no matter what they did in terms of communicating issues upwards, management did not act preventatively, but rather waited until crisis situations loomed before reacting. They responded to this by becoming "disjointed from management" (P11S) and focusing on what they could control within the immediate environment of their unit, thus maintaining the status quo of four units working more or less independently within the department in opposition of goal of the organisation, which was to merge the units (See Organising). That this was the case was supported by points raised in the second external review, which identified "the relationship between some senior medical staff and the NHS $x x x x$ senior leadership" as one of issues raised for external review (see Belonging). The reports brought the tensions into the open, drawing attention to the fact that "there were a number of things which people were dissatisfied with and there was a real momentum to actually change some of those things" [P9AM].

In short, it seemed that managers and surgeons had long been in opposition, with the former ignoring the need to accommodate training, and the latter responding by taking a protectionist stance. The third group in the equation, the trainees, reported that they tended to focus in on managing their own educational needs within the above context of an adversarial institutional and professional relationship. Within paradox theory, this kind of response is considered opposing, as each party stuck to their own views and goals with no apparent compromise (see Table 2). There was also an element of a suppressing response, with management seeming to ignoring requests and communications from clinicians.

When the tensions between service and training in the surgical unit became visible after the external reviews, several things happened which influenced Performing. First, the suspension of two senior (Consultant level) surgeons redefined relationships and priorities within the unit, and between the 
clinicians and managers. This can be considered a splitting response (see Table 2) - separating elements (in this case separating certain individuals from the wider unit - as a means of addressing the issue. This in turn seemed to allow the remaining consultants to respond by adjusting in terms of working with the trainees for mutual benefit. For example, they engaged more directly with trainee needs, working with them to develop ways of accommodating education and training more effectively, and building relationships (see Belonging). Relationships between surgeons and managers also seemed more accommodating. Second, mangers responded to the criticisms raised in the external reports by adjusting, by giving resource to facilitate change to the surgical unit (see Organising).

\section{Organising}

At the individual (Performing) level, there was the view that "people [clinicians] in xxx [the hospital] are quite committed to education" (Р3T). However, this was not reflected at an organisational, or organising level where the importance of training seemed to be unclear, or at best assumed rather than explicit, even after the external reviews:

You know, it's assumed, we're in a teaching hospital, therefore we will teach, but it isn't necessarily a focus of discussion at management meetings, about are we putting the right support in place for that? Are we doing the best that we could as a team? That's not on many agendas, many management agendas (P13AM).

There seemed to be an assumption that training would be delivered, but explicit organisational support for doing so was lacking, indicating that the goals of service and training were compartmentalized (splitting). That this tension did not appear to be taken seriously at an organisational level was further demonstrated by a lack of responsiveness from hospital managers when a significant proportion of the general surgery trainees had described their training environment as 'not supportive' in an influential national survey (GMC, 2016). This feedback had the potential consequence of the general surgery department having its training status (and trainees, removed), which would have in turn impacted adversely on both the institution's reputation and the general surgical department's capacity to deliver service. Surgical trainees had communicated their views using a powerful tool, yet from the perspective of the clinical surgical staff (Foundation Programme doctors, surgical trainees/residents and Consultants), the managers did not seem to respond to this feedback (supressing response: and see Belonging for further discussion). Indeed, all the surgical staff we interviewed were clear in their views that management did not take ownership of training and 
only responded when things were critical: "until we were leaning on them saying that, you know, people are going to die, nothing was done" (P2T).

Yet on the other hand, as a result of the reports, the organisation had provided the general surgery department with additional resources to support organisational change. This support had been requested by the consultant surgeons, and agreed by the hospital/organisation's chief executive officer. It took the form of change management staff, one of whom helped the unit create a vision for a modern surgical service, including how training would be embedded, and another, an administrator, who supported them to take forward various workstreams (including an education/training stream) to achieve this.

While this resource was viewed positively by clinicians, and could be at least a first glimpse be seen as an adjusting response, the paradox lens suggests that it was unlikely to lead to real change for two reasons. First, it was time-limited. However, was a tension between the wish to change and the timeframe imposed for this change - "we've come out of rock bottom but we're still this steep climb and we're still pretty far away from where, actually really far away from where we want to get" [P12S] yet the additional support was time limited and there was an expectation from the organisation that change would be implemented within a set timeframe ("there are some radical ideas but we've six, nine, 12 months to actually implement" [P9AM]). Because of this, the response of extra resource was unlikely to address the tension between patient care and training in a sustainable way. Second, there was a sense that training remained compartmentalized, or split, from service, and the responsibility for addressing training issues still remained with the surgeons (albeit with some additional administrative support), rather than the balance between education and training shifting in a real sense within the hospital structures.

\section{Belonging}

Consultant surgeon attitudes towards the trainees and training seemed to significantly impact on the trainees' sense of belonging, feeling valued and supported (see also Performing), and being a part of the team: "the good consultants are the ones who identify patients [to discuss], interact with the students on ward rounds, and make them feel at ease" (P3T). Being approachable and engaging with the trainees by "finding out their names" (P14E) was conducive to a better learning environment, compared to the consultant "just showing up around lunchtime, and insisting on a ward round" (P2T). The importance of belonging is relevant to consultants and the surgical team too: having "collective responsibility for being part of the service" (P13E) with trainers and trainees, along with the rest of the surgical staff, working together as a department (adjusting). Developing a cohesive team atmosphere 
within a unit was "the result of the consultants' attitude to it" (P5S) and the efforts to do so had been noticed by trainees ("I do think it had improved in terms of being able to access senior help" [P10T]). However, there were different perspectives on the same situation (Performing). Trainees/residents, particularly those in the early stages of training, rotate through units and departments and "it can be difficult to build up a rapport with them and therefore give them the training opportunities that they require" (P12S). Trainees can feel isolated, outside the team and unable to "contribute in quite the same way" (P13E), and find it more difficult to become a "valued" member of the team (P10T). This lack of belonging, coupled with the requirements of a competency-based system for medical training, resulted in individual trainees focusing on their own needs (see earlier/Performing). This tension between belonging and performing was not wholly due to the issues specific to the general surgery unit. Rather the main contributing factors to trainees not feeling that they belonged were more general, related to the nature of rotations and the complexity of how they were managed. For example, one trainee/resident discussed a situation where his/her rotations were changed by the hospital at short notice, to suit the service: "[it was] a reflex thing to try and solve the problem which, you know, clearly wasn't approved by the proper people, didn't take into account my training" [P2T]).

\section{Learning}

Underpinning the issues described above was a perceived history of poor role modelling within the department, as highlighted in the external reviews. Conflicts and poor interpersonal relationships between the consultant body manifested as petty arguments, "aggressive behaviour" (P12S), controlling actions (e.g. only working with certain trainees) and dysfunctional interpersonal relationships ("The hierarchies [within the surgical department] became toxic" (P11S). Disagreements amongst the surgical consultants leached into the training environment, "with heated debates in theatre" (P2T) in front of the trainees who were in "a very uncomfortable situation with a case of just getting your head down and shutting up" (Р3T), leading to "a lot of gossip and speculation" (P4T). These behaviours were then seen as acceptable by the trainees who then internalised that "this is how things get done" and behaved in the same way, for example, sending out "shocking [inappropriate] emails" (P6AM). This was recognised widely but nothing was done (supressing) until the issues became public: “People knew that things weren't right, people knew that it wasn't an ideal environment. But what is and how many other departments, were they just unlucky? Because there are cultures which aren't great. So they needed that catalyst." [P9AM]. When the individuals to whom this behaviour was ascribed were suspended, relationships improved (the atmosphere of the department is better and that's what probably helps more than anything else" (Р3T). 
The external reports and their consequences also encouraged adjustment, or change, in terms of surgical trainees feeling empowered to speak out where they had concerns about their own training: "I felt more inclined to raise that [training being second line to service provision]" (P2T). Those who had been working and training within general surgery over a number of years noticed change efforts "after the xxx report there seemed to be an effort to try and make teaching more of an issue ... new efforts are being made [e.g., protected time for teaching, weekly morbidity and mortality meetings] and they're fairly apparent that they're going to, you know, provide better teaching" (Р3T). 


\section{Discussion}

We observed evidence of paradoxical tensions throughout the data, the responses to which mainly seemed to threaten progress, or change, in relation to improving surgical training in the unit under study.

Tensions were apparent in the data, with managers, surgeons and trainees/residents in conflict with each other due to different goals/priorities and divergent perspectives on the same issue of balancing service and training with insufficient time and resources. This adversely impacted on relationships across and within groups, with trainees feeling isolated, managers and surgeons in conflict, and trainees being exposed to poor role modelling. Assumptions were made regarding the motivational factors of others that were considered to relate to both individual and organisational characteristics. The external reports brought these long-standing tensions to the surface and necessitated responses. Yet while relationships and communication improved, the approach, or response, to getting a better balance maintained the "compartmentalisation" of training rather than acknowledging training and service are inter-dependent. If we assume that the between service and training in a university hospital unit is an interdependent and persistent paradox, then it needs more than a "sticking plaster" (temporary) solution to lead to real change.

We also found paradoxes which have been observed internationally, such as surgical trainees/residents perceive that too much of their job is service and too little is education, but their trainers do not agree, viewing service as educational $(2,59,60)$. Clinicians' disaffection with nonclinical management and strained doctor-manager relationships have been documented for many years in many different contexts $(61,62)$. Our empirical data highlights that disconnections between managers, Consultants and trainees are due to quite fundamentally divergent goals and positions relating to training and service $(27,28)$.

Yet are the goals and positions of training and service so different and can they really be separated? Trainees/residents deliver patient care. In the longer-term, service delivery depends on training appropriate numbers of surgeons (in this instance) to progress upwards through the stages of medical education and training as is customary, replacing those who are retiring and ensuring a steady flow of training places - and supervisors - for the next generation of trainees/residents, to meet the anticipated healthcare needs of the population in the future (63-65). Anecdotal reports suggest that a hospital with a bad reputation for training will struggle to attract trainees and new consultants, and this will adversely impact on service delivery in both the immediate and longerterm. Patient care and training are hence of equal importance. One cannot exist without the other. 
Reframing the paradox between the two in a way which affirms them as equally valid (66), and persistent (26), which may encourage adjusting responses as an ongoing activity in the pursuit of effective working partnerships between trainees, trainers and managers (31). If the tensions between service and training in the surgical unit had been acknowledged openly and constructively, and managers, surgeons and residents had worked together to try to accommodate both sides of the paradox, then issues with education and training could have been addressed earlier. This could have led to the ameliorating of the need for critical external reviews, poor working relationships and bad press. Alternatively, perhaps the crisis was necessary to bring tensions to the surface. Either way, the opportunity for the development of a relational understanding (67) was lost. Relational understanding requires an openness to experience, a willingness to engage in a dialogue that can challenge self-understanding. To be in this type of dialogue requires listening to others and risk confusion/uncertainty both about ourselves, and about other people we seek to understand (67, $p$ 458). Nonetheless, we argue that this risk is worth it in this type of training/service context, given the severity of the potential detrimental effects on patients, trainees and more broadly, the production of an effective healthcare workforce.

Our findings also have research implications. The main theoretical frameworks presented in studies of work-based medical training tend to be socio-cultural $(68,69)$. We took a different stance, drawing on management science theory to provide a fresh perspective on a well-acknowledged issue in response to calls in the literature to focus on the organisational context of postgraduate training (70-73), to allow us progress knowledge from describing service-training tensions to understanding how people may react to them. An understanding of this may help all those involved in surgical training, in any context, to think differently about how to manage persistent tensions.

Borrowing theory from other disciplines is not new in medical education but our knowledge of the literature suggests that management science theory is rarely adopted. While bringing something new to the field in this way is useful, as with any theory borrowing, we carefully considered the theory, and checked its assumptions (74) were congruent with our approach, question and context before final selection (75). For example, we were interested in individual responses while acknowledging the interactions between systems and people, so used a paradox approach which bridges these positions (26). We were reassured by the use of Smith and Lewis's paradox theory in other healthcare contexts (28). However, the transferability of paradox theory in explaining responses to tensions between training and service remains to be tested out in other contexts. Finally, paradox theory illuminated certain aspects of the data (34): another lens may have emphasised different aspects of the problem, such as the nature of the power relationships and social dynamics between managers and surgeons $(76,77)$. 
The case study approach is suitable for organisational contexts (78) and has been used previously to look at organisational paradoxes (79). There are different views on case study design (80): our epistemological stance and approach to gathering and analysing data were most closely aligned with Yin's perspective $(36,43)$ : for example, we set out to examine an extreme case with a clear research plan and protocols, addressed construct validity by checking data credibility and used a theoretical framework to summarise the findings and to aid analytic (conceptual) generalisability $(81,82)$. However, within the limits of a single-site case study our interview data was sufficient and our interviewees appropriate for the research question (58).

It may be that the use of an extreme case limits the transferability of the findings. Multi-site or comparative case studies would be a useful next step in examining how stakeholders in different surgical settings, or indeed any hospital environment, manage and respond to competing tensions between service and training $(36,43,44)$.

We used a combination of documentary evidence and interviews to collect empirical data. This is a common traingulation of data sources in management science $(83)$ and education $(84,85)$, but perhaps less so in medical education (although for a recent exception, also set in a surgical community, please see 86). However, all data qualitative collection approaches have strengths and weaknesses (87-88). Given our specific focus, interviewees may have wish to give social desirably responses, but the tone of the interviews did not suggest this was this case - although it would be fascinating to do a linguistic analysis to explore this further (89).

Our study design did not allow us to capture longitudinal processes (e.g., how things changed over time), or if the tensions observed differed by stage of training or position. That said the goal of the study was not assess change longitudinally, but to interrogate the experiences, perceptions and purported responses of the interviewees in a surgical training and service context during a time of great upheaval. While this context may reduce the conceptual generalizability of this study, the crisis brought persistent tensions to the surface where they were more observable $(26,29,30)$. Jansson states that "Nothing, or let's say very few things, are as difficult as the nature of a university hospital" because of the competing missions of patient care and teaching/training (28, p659). This empirical study is the first to look at these tensions with a management science lens, and in a beleaguered surgical setting, and hence provides a new perspective on how these tensions could be understood and managed, extends knowledge and stimulates discussion and thinking in the field. We urge those involved in researching surgical and other postgraduate training to continue this discussion by considering how thinking differently about persistent tensions may help in terms of identifying, and supporting, adaptive responses. 


\section{References}

1. Goodrick E, Reay T. Constellations of institutional logics. Work and Occupations 2011; 38(3): 372416.

2. Kesselheim JC, Sun PMS, Woolf AD, London WB, Boyer D. Balancing education and service in Graduate Medical Education: Data from Paediatric trainees and program directors. Academic Medicine 2014; 89 (4): 652-657.

3. Reay T, Hinings CR. Managing the rivalry of competing institutional logics. Organization Studies 2009; 30(6): 629-652.

4. Stok-Koch L, Bolhuis S, Koopmans R. Identifying factors that influence workplace learning in postgraduate medical education. Educ Heal. 2007;20(1):1-8.

5. Pierce, J.C. The paradox of physicians and administrators in health care organizations. Health Care Manag. Rev. 2000, 25, 7-28.

6. Pratt DD, Arseneau R, Collins JB. Reconsidering "good teaching" across the continuum of medical education. J Contin Educ Health Prof. 2001;21(2):70-81.

7. OECD (2014). Health statistics: Frequently requested data. www.oecd.org/els/healthsystems/oecd-health-statistics-2014-frequently-requested-data.htm [Accessed 5 May 2015].

8. Ferlie, E., Ashburner, L., Fitzgerald, L. \& Pettigrew, A. (1996). The new public management in action. Oxford: Oxford University Press.

9. Busari JO, Koot BG. Quality of clinical supervision as perceived by attending doctors in university and district teaching hospitals. Medical Education 2007; 41:957-964.

10. General Medical Council (GMC). The state of medical education and practice in the UK. 2011 http://www.gmc-uk.org/State of medicine Final web.pdf 44213427.pdf (last accessed 28th August 2016).

11. Henning M, Shulruf B, Hawken S, Pinnock R. Changing the learning environment: the medical student voice. The Clinical Teacher 2011; 8(2): 83-87.

12. Turner TL, Fielder E, Ward MA. Balancing Service and Education in Residency Training. A Logical Fallacy. JAMA Pediatrics 2016;170(2):101-102.

13. Temple J (2010) Time for Training, A review of the impact of the European Working Time Directive London, Medical Education England. 
14. Greenway D. Shape of Medical Training: securing the future of excellent patient care. 2013 http://www.shapeoftraining.co.uk/static/documents/content/Shape of training FINAL Report.pdf 53977887.pdf (Accessed 15 ${ }^{\text {th }}$ May 2017).

15. General Medical Council (GMC). National training survey 2016. http://www.gmcuk.org/education/surveys.asp (last accessed 22nd March 2017)

16. Quinn A, Burnett P. Service versus education: finding the right balance: a consensus statement from the Council of Emergency Medicine Residency Directors 2009 Academic Assembly “Question 19" working group. Academic Emergency Medicine 2009; 16: (suppl 2): S15-S18.

17. Rimmer A. Workloads threaten to undermine doctors' training, GMC finds. BMJ 2016; 355: i6495 doi: 10.1136/bmj.i6495 (Published 1 December 2016)

http://www.bmj.com/content/bmj/355/bmj.i6495.full.pdf (Accessed 22nd March 2017).

18. Davenport DL, Henderson WG, Hogan S, Mentzer RM Jr, Zwischenberger JB. Participants in the Working Conditions of Surgery Residents and Quality of Care Study. Surgery resident working conditions and job satisfaction. Surgery 2008; 144(2):332-338, e5.

19. Wallenburg I, Pols J, de Bont A. 'You need to bond with the ones you train': mixing epistemic cultures in medical residency training. Evidence \& Policy: A Journal of Research, Debate and Practice. 2015 Aug 21;11(3):397-414.

20. Wallenburg I, Hopmans CJ, Buljac-Samardzic M, den Hoed PT, IJzermans JN. Repairing reforms and transforming professional practices: a mixed-methods analysis of surgical training reform. Journal of Professions and Organization. 2016 Mar 1;3(1):86-102.

21. Australian Medical Association. AMA Junior Doctor Training, Education and Supervision Survey: Report of Findings. 2009.

https://ama.com.au/sites/default/files/documents/AMA TES Report 1.pdf [Accessed 9 August 2017].

22. Putnam, L. L. (1986). Contradictions and paradoxes in organizations. In L. Thayer (Ed.), Organization-communication: Emerging perspectives 1 (pp. 151-167). Norwood, NJ: Ablex.

23. Lewis MW. Exploring Paradox: Toward a More Comprehensive Guide. Academy of Management Review 2000; 25: 760-76.

24. Poole MS, van de Ven A. Using Paradox to Build Management and Organization Theories. The Academy of Management Review 1989; 14: 562-578. 
25. Eisenhardt KM, Martin JA. Dynamic capabilities: What are they? Strategic Management Journal 2000; 21: 1105-1122.

26. Smith WK, Lewis MW. Toward a theory of paradox: a dynamic equilibrium model of organizing. Academy of Management Review 2011; 36 (2): 381-403.

27. Choi S, Holmberg I, Löwsted J, Brommels M. Executive management in radical change: the case of the Karolinska university hospital merger. Scandinavian Journal of Management 2011; 27 (1): 1123.

28. Jansson N. Permanent tensions in organization: An obstacle or an opportunity for the change discourse? Journal of Health Organization and Management 2015; 29 (6): 654-699.

29. Clegg S, Cunha JV, Cunha MP. Management Paradoxes: A Relational View. Human Relations 2002; 55(5): 483-503.

30. Lüscher LS, Lewis MW. Organizational change and managerial sensemaking: working through paradox. Academy of Management Journal 2008; 51 (2): 221-240.

31. Jarzabkowski P, Le, JK, Van de Ven AH. Responding to competing strategic demands: How organizing, belonging, and performing paradoxes coevolve. Strategic Organization 2013; 11 (3): 245280.

32. Weick K, Quinn R. Organizational change and development. Annual Review of Psychology 1999; 50: $361-386$.

33. Fiol CM, Lyles M. Organizational Learning. Academy of Management Review 1985; 10(4): 80313.

34. Bordage G. Conceptual frameworks to illuminate and magnify. Medical Education 2009 43: 312319.

35. Kelle, U. (1995). Theories as Heuristic Tools in Qualitative Research', in I Maso, PA Atkinson, S Delamont and JC Verhoeven (eds) Openness in Research. The Tension between Self and Other, pp.33-50. Assen: van Gorcum.

36. Yin, Robert K. (2003a). Case study research, design and methods (3rd ed). Thousand Oaks: Sage. 37. Evans PAL. HRM on the edge: a duality perspective. Organization 1999; 692): 325-338.

38. Fry H, Kneebone R. Surgical Education: Theorizing an Emerging Domain. London: Springer 2011. 
39. Dawe SR, Pena GN, Windsor JA, Broeders JA, Cregan PC, Hewett PJ, Maddern GJ. Systematic review of skills transfer after surgical simulation-based training. British Journal of Surgery 2014; 101: 1063-76.

40. Cleland JA, Walker K, Gale M, Nicol LJ. Simulation-based education: Understanding the complexity of a surgical training "Boot Camp". Medical Education, 2016: 50: 829-841.

41. Bleakley, A., Boyden, J., Hobbs, A., Walsh, L., \& Allard, J. (2006). Improving teamwork climate in operating theatres: The shift from multiprofesisonalism to interprofessionalism. Journal of Interprofessional Care, 20, 461-470.

42. Fenwick T. Understanding relations of individual - collective learning in work: A review of research. Management Learning 2008; 39: 227-243.

43. Yin, Robert K. (2003b). Applications of case study research (2nd ed). Thousand Oaks: Sage.

44. Stake, R., The art of case research. 1995, Thousand Oaks, CA: SAGE Publications.

45. Nelson EC, Batalden PB, Huber TP, et al. Microsystems in health care: Part 1. Learning from highperforming front-line clinical units. The Joint Commission journal on Quality Improvement 2002; 28: 472-493.

46. Ragin CC. (1992) "Casing" and the process of social inquiry. In C. C. Ragin \& H. S. Becker (Eds.), What is a case? Exploring the foundations of social inquiry (pp. 217-226). Cambridge, UK: Cambridge University Press.

47. Flyvbjerg B. Five Misunderstandings About Case-Study Research. Qualitative Inquiry 2006; 12 (2): $219-24$.

48. General Medical Council (GMC) Promoting excellence: standards for medical education and training. 1st January 2016. http://www.gmc-uk.org/education/standards.asp (last accessed 15 may 2017).

49. Cannon M, Edmondson A. Confronting failure: antecedents and consequences of shared beliefs about failure in organizational work groups. Journal of Organizational Behavior 2001; 22: 161-77. 50. Sitkin S. Learning through failure: the strategy of small losses. Research in Organizational Behaviour 1992; 14: 231-66.

51. Fink, S. (1986). Crisis management: Planning for the inevitable. New York, NY: AMACOM. 
52. Patton, MQ. (2001). Qualitative Research and Evaluation Methods (2nd Edition). Thousand oaks, CA: Sage Publications.

53. Improving Surgical Training (IST) 2015 https://www.rcseng.ac.uk/careers-in-surgery/trainees/ist/ [accessed 16 August 2017]

54. Royal College of Surgeons. 2016. A Question of Balance: The extended surgical team. https://www.rcseng.ac.uk/standards-and-research/standards-and-guidance/servicestandards/extended-surgical-team/

55. Thomas C, et al. Does UK surgical training provide enough experience to meet today's training requirements? BMJ Careers, 11 May 2015.

56. Braun V, Clarke V. Using thematic analysis in psychology. Qualitative Research in Psychology 2006; 3 (2): 77-101.

57. McMillan W. Theory in healthcare education research: the importance of worldview. In: Cleland JA, Durning SJ, eds. Researching Medical Education. Oxford: Wiley 2015; 15-23.

58. Varpio L, Ajjawi R, Monrouxe LV, O'Brien, Rees CE. Shedding the cobra effect: problematising thematic emergence, triangulation, saturation and member checking. Medical Education 2017; 51: $40-50$

59. Reines HD, Robinson L, Nitzchke S, Rizzo A. Defining service and education: the first step to developing the correct balance. Surgery 2007;142(2):303-310.

60. Sanfey H, Cofer J, Hiatt JR, Hyser M, Jakey C, Markwell S et al. Service or Education: In the Eye of the Beholder. Archives of Surgery 2011;146(12):1389-1395.

61. Bohmer R. (2012). The instrumental value of medical leadership: Engaging doctors in improving services. https://www.kingsfund.org.uk/sites/files/kf/instrumental-value-medical-leadershiprichard-bohmer-leadership-review2012-paper.pdf

62. Crosson FJ. Improving the doctor-manager relationship. Kaiser Permanente: a propensity for partnership. BMJ 2003; 326: 654.

63. Addicott R, Maguire D, Honeyman M, Jabbal J. Workforce planning in the NHS. The King's Fund http://www.kingsfund.org.uk/sites/files/kf/field/field_publication_file/Workforce-planning-NHSKings-Fund-Apr-15.pdf (accessed 1st August 2016).

64. Gorman D. Developing health care workforces for uncertain futures. Academic Medicine 2015; 90: 400-408. 
65. Baicker K, Chandra A. Medicare spending, the physician workforce, and beneficiaries' quality of care. Health Aff (Millwood) 2004 Jan-Jun; Suppl Web Exclusives:W4-184-97.

http://content.healthaffairs.org/content/early/2004/04/07/hlthaff.w4.184.full.pdf+html (accessed 1st August 2016).

66. Kraatz, MS \& Block, ES. (2008) Organizational Implications of Institutional Pluralism, in R. Greenwood, C. Oliver, K. Sahlin and R. Suddaby (eds) The SAGE Handbook of Organizational Institutionalism. London: Sage, pp. 243-275.

67. Schwandt TA. On Understanding Understanding. Qualitative Enquiry 1999; 5: 451-464.

68. Lave J, Wenger E. Situated Learning: Legitimate Peripheral Participation. Cambridge University Press; 1991.

69. Eraut M. Informal learning in the workplace. Stud Contin Educ. 2004;26(2):247-273.

70. Skipper M, Nøhr SB, Jacobsen TK, Musaeus P. “Organisation of workplace learning: a case study of paediatric residents' and consultants' beliefs and practices." Adv Heal Sci Educ. 2015; 21:677-694.

71. van de Wiel MWJ, Van den Bossche $\mathrm{P}$, Janssen $\mathrm{S}$, Jossberger $\mathrm{H}$. Exploring deliberate practice in medicine: how do physicians learn in the workplace? Adv Health Sci Educ Theory Pract. 2011;16(1):81-95.

72. Sargeant J, Mann K, Sinclair D, et al. Learning in practice: experiences and perceptions of highscoring physicians. Acad Med. 2006;81(7):655-660.

73. Nothnagle M, Anandarajah G, Goldman RE, Reis S. Struggling to be self-directed: residents' paradoxical beliefs about learning. Acad Med. 2011;86(12):1539-1544.

74. Hudson, L., and Ozanne, J. (1988). Alternative Ways of Seeking Knowledge in Consumer Research. Journal of Consumer Research, 14(4), 508-521.

75. Murray JB, Evers DJ. (1989). Theory Borrowing and Reflectivity in Interdisciplinary Fields. In Advances in Consumer Research Volume 16 (Ed: TA Srull), Provo, UT : Association for Consumer Research, 647-652.

76. Fenwick T. Understanding relations of individual - collective learning in work: A review of research. Management Learning 2008; 39: 227-243.

77. Halford S, Leonard P. Place, space and time: contextualizing workplace subjectivities. Organization Studies 2005; 27: 657-676. 
78. Siggelkow, N. Persuasion with case studies. Academy of Management Journal 2007; 50: 20-24.

79. Andriopoulos C, Lewis M. Exploitation-exploration tensions and organizational ambidexterity: Managing paradoxes of innovation. Organizational Science 2009; 20(4): 696-717.

80. Yazan B. Three Approaches to Case Study Methods in Education: Yin, Merriam, and Stake. The Qualitative Report 2015; 20: 134-152.

81. Eaton RM. The Value of Theories. The Journal of Philosophy 1921; 18 (25): 682-690.

82. Kohlbacher F. The Use of Qualitative Content Analysis in Case Study Research. Forum:

Qualitative Social Research 2006; 7 (1) http://www.qualitative-

research.net/index.php/fqs/article/view/75

83. Jones M, Morrison-Saunders A. Environmental Impact Assessment Review 2017; 64: 131-138.

84. Sulistiyo U, Mukminin A, Abdurrahman K, Haryanto E. Learning to teach: A case study of student teachers' practicum and policy recommendations. Qualitative Report 2017; 22: 712-731.

85. Lai M, Lam KM, Lim CP. Design principles for the blend in blended learning: A collective case study Teaching in Higher Education 2016: 21: 716-729.

86. Kitto SC, Grant R, Peller J, Moulton C-A, Gallinger S. What's in a name? Tensions between formal and informal communities of practice among regional subspecialty cancer surgeons. Advances in Health Sciences Education 2017; 9 June: 1-19.

87. DiCicco-Bloom B, Crabtree BF. The qualitative research interview. Medical Education 2006; 40: 314-321.

88. Lincoln YS, Guba EG. Naturalistic Enquiry. 1985. Beverley Hills, CA: Sage.

89. Wodak, R. Pragmatics and Critical Discourse Analysis: A Cross-disciplinary Inquiry. Journal of Pragmatics and Cognition 2007; 15(1): 203-27. 


\section{Box 1: A brief overview of postgraduate medical training in the UK}

Junior doctors in the UK learn their craft in approved training posts in centres deemed capable of delivering training by the regulator, the General Medical Council (GMC). They have clinical responsibility under supervision which encompasses the principle of developing independent practice whilst maintaining an environment that is safe for patients.

After graduating from medical school, doctors work in Foundation Programmes (FP) for two years where they acquire full registration with the GMC and satisfy standards of knowledge, skill and behavioural attributes specified in the Foundation curriculum. Thereafter, they progress to specialty training in one of the many specialties recognised by the GMC, including the surgical specialties (e.g., general surgery, orthopaedics).

Specialty training programmes extend over $2-8$ years during which doctors practice across a range of experience relevant to their future career in that specialty, housed in the context of learning in the workplace. This may involve a variety of specialties or be focused on aspects of one specialty but obtaining exposure across the breadth of that specialty.

Training is standardised to curricula written by the UK Medical Royal Colleges and Faculties, and approved by the GMC. These curricula include formative, usually workplace based, and summative, usually formal written and practical examination, assessment of knowledge, skills and behavioural competencies. These are tied to curricula and to generic practice guidance published by the GMC (48).

All medical training is regulated by the General Medical Council (GMC) whose standards for medical education and training require healthcare organisations "to provide high-quality educational experiences in safe, effective and appropriately-supported learning environments" ( $\mathrm{px}$ ). To monitor this, the GMC carries out annual surveys of trainees and trainers, feeding the results of these surveys back to organisations, who are expected to use this information to review and improve training (ref NTS). Units or locations with persistently poor educational outcomes, in areas such as supervision, workload, access to educational opportunities, are placed in "enhanced monitoring" to review improvement plans, and monitor their implementation. 


\begin{tabular}{|c|c|c|c|}
\hline Paradox & Explanation & Level & Outcome \\
\hline Performing & $\begin{array}{l}\text { Where individuals are } \\
\text { required to perform } \\
\text { multiple, possibly } \\
\text { competing roles and tasks } \\
\text { (28) }\end{array}$ & $\begin{array}{l}\text { Micro - individual } \\
\text { response to conflicting } \\
\text { demands in their own } \\
\text { roles or arising from the } \\
\text { roles of others with whom } \\
\text { they share joint tasks } \\
\end{array}$ & $\begin{array}{l}\text { Contradictory actions as } \\
\text { actors try to perform } \\
\text { competing goals, or work } \\
\text { towards different versions of } \\
\text { success and failure (26) }\end{array}$ \\
\hline Organising & $\begin{array}{l}\text { Where there are tensions } \\
\text { between different possible } \\
\text { ways of organising people } \\
\text { and work }\end{array}$ & $\begin{array}{l}\text { Macro - the structural } \\
\text { conditions in which actors } \\
\text { function and experience } \\
\text { tensions }\end{array}$ & $\begin{array}{l}\text { Tensions between different } \\
\text { organisational tasks and } \\
\text { functions the interplay } \\
\text { between structures that } \\
\text { shape actions, and actions } \\
\text { which shape structures }\end{array}$ \\
\hline Belonging & $\begin{array}{l}\text { Closely related to } \\
\text { individual identity, and } \\
\text { tensions between the } \\
\text { individual and the } \\
\text { collective }\end{array}$ & $\begin{array}{l}\text { Meso - the interaction } \\
\text { between individuals, their } \\
\text { immediate group and the } \\
\text { wider organisation }\end{array}$ & $\begin{array}{l}\text { Actors struggle to reconcile } \\
\text { the values and beliefs of their } \\
\text { reference group with those } \\
\text { of other groups and the } \\
\text { wider organisation }\end{array}$ \\
\hline Learning & $\begin{array}{l}\text { Related closely to change, } \\
\text { reflecting tensions which } \\
\text { arise when new replaces } \\
\text { old and people learn } \\
\text { during the change (32) }\end{array}$ & $\begin{array}{l}\text { Multi-level, occurring both } \\
\text { within actors and } \\
\text { organisations ( } 33 \text { ). }\end{array}$ & $\begin{array}{l}\text { "An underpinning tension } \\
\text { contributing to the other } \\
\text { paradoxes" (31, p. 248). }\end{array}$ \\
\hline
\end{tabular}


Table 2. Definitions and illustrations of responses to paradox. Reproduced with permission from Jarzabkowski et al, adjusted to provide illustrations relevant to medical education and training.

\begin{tabular}{|c|c|c|c|}
\hline Construct and definition & Characteristics & Impact & Illustration \\
\hline $\begin{array}{l}\text { Splitting response } \\
\text { A response to tension that } \\
\text { involves separating } \\
\text { contradictory elements } \\
\text { either temporally (dealing } \\
\text { with one, then the other) } \\
\text { or spatially } \\
\text { (compartmentalizing } \\
\text { elements into different } \\
\text { areas) }\end{array}$ & $\begin{array}{l}\text { Type of response to } \\
\text { paradoxical tension } \\
\text { (defensive) } \\
\text { Core focus: dealing } \\
\text { with tension by } \\
\text { separating elements }\end{array}$ & $\begin{array}{l}\text { Temporary } \\
\text { relief from } \\
\text { tension } \\
\text { Potential for } \\
\text { progress }\end{array}$ & $\begin{array}{l}\text { Compartmentalizing goals, for } \\
\text { example, compartmentalizing } \\
\text { education and training into } \\
\text { different divisions, or to } \\
\text { specific groups of stakeholders }\end{array}$ \\
\hline $\begin{array}{l}\text { Suppressing response } \\
\text { A response to tension that } \\
\text { involves prioritizing one } \\
\text { element and allowing it to } \\
\text { dominate or overrule the } \\
\text { other element of a } \\
\text { paradox }\end{array}$ & $\begin{array}{l}\text { Type of response to } \\
\text { paradoxical tension } \\
\text { (defensive) } \\
\text { Core focus: dealing } \\
\text { with tension by } \\
\text { overruling/ } \\
\text { dominating }\end{array}$ & $\begin{array}{l}\text { Temporary } \\
\text { relief from } \\
\text { tension } \\
\text { Potential for } \\
\text { progress }\end{array}$ & $\begin{array}{l}\text { Overruling requests from the } \\
\text { other party, such as the need } \\
\text { for additional staff to cover } \\
\text { service and training. The } \\
\text { suppressed party tries to work } \\
\text { around suppression of its } \\
\text { needs, such as a unit trying } \\
\text { compensate for lack of } \\
\text { trainers by sending learners } \\
\text { on courses rather than sorting } \\
\text { the issue directly }\end{array}$ \\
\hline $\begin{array}{l}\text { Opposing response } \\
\text { A response to tension that } \\
\text { involves parties supporting } \\
\text { contradictory elements of } \\
\text { a paradox engaging in } \\
\text { active confrontation and } \\
\text { conflict that polarize } \\
\text { paradoxical elements }\end{array}$ & $\begin{array}{l}\text { Type of response to } \\
\text { paradoxical tension } \\
\text { (defensive) } \\
\text { Core focus: dealing } \\
\text { with tension by } \\
\text { opposing and } \\
\text { polarizing }\end{array}$ & $\begin{array}{l}\text { Temporary } \\
\text { relief from } \\
\text { tension } \\
\text { Potential for } \\
\text { progress } \\
\text { Potential for } \\
\text { vicious cycle }\end{array}$ & $\begin{array}{l}\text { Having direct confrontations } \\
\text { that polarize positions, such as } \\
\text { senior clinical staff refusing to } \\
\text { supervise trainees as there is } \\
\text { no time for this in their job } \\
\text { plan. Managers refusing to } \\
\text { fund new posts. Each side } \\
\text { sticks to their own view of } \\
\text { tasks and goals, with no } \\
\text { compromise on either side. }\end{array}$ \\
\hline $\begin{array}{l}\text { Adjusting response } \\
\text { A response to tension that } \\
\text { recognizes that both poles } \\
\text { of the paradox are } \\
\text { important and } \\
\text { interdependent and thus } \\
\text { both need to be } \\
\text { accommodated }\end{array}$ & $\begin{array}{l}\text { - Type of response to } \\
\text { paradoxical tension } \\
\text { (active) } \\
\text { - Core focus: dealing } \\
\text { with tension by } \\
\text { accommodating } \\
\text { each other's needs }\end{array}$ & $\begin{array}{l}\text { Longer term } \\
\text { relief from } \\
\text { tension } \\
\text { Potential for } \\
\text { progress } \\
\text { Potential for } \\
\text { virtuous cycle }\end{array}$ & $\begin{array}{l}\text { Sides accommodating each } \\
\text { other, for example, by } \\
\text { Managers and clinicians, or } \\
\text { trainers and trainees, working } \\
\text { together to mutual gain. }\end{array}$ \\
\hline
\end{tabular}

